\title{
Design and test of 2ZYM-2 potted vegetable seedlings transplanting machine
}

\author{
Xin Jin ${ }^{1,2}$, Qun Cheng ${ }^{2}$, Bo Zhao ${ }^{3}$, Jiangtao $\mathrm{Ji}^{1,{ }^{2 *}}$, Mingyong $\mathrm{Li}^{1}$ \\ (1. College of Agricultural Equipment Engineering, Henan University of Science and Technology, Luoyang 471003, China; \\ 2. Collaborative Innovation Center of Machinery Equipment Advanced Manufacturing of Henan Province, Luoyang 471003, China; \\ 3. Chinese Academy of Agricultural Mechanization Sciences, Beijing 100083, China)
}

\begin{abstract}
In order to improve the efficiency and quality of transplanting vegetables in dry land, based on the seedling technology, transplanting effect and analysis of the planting process, a potted vegetable seedlings transplanting machine was designed. It mainly comprised rotary disc type feeding mechanism, five-bar duckbill type planting mechanism (simulated duckbill mechanism, disc cam, connecting rod, crank, fork, cable) and power transmission system. Based on the physical parameters of the seedlings and design requirements, it was determined that the diameter of the duckbill was $D=90 \mathrm{~mm}$, the opening and closing angle was $25^{\circ}$, and the taper angle was $17^{\circ}$. A test bench with adjustable parameters was built by analyzing the structure of the planting mechanism and the motion of the working process. The digital speckle technique was used to optimize the parameters, so that the length of the crankshaft I was $S_{1}=100 \mathrm{~mm}$, the length of the crankshaft II was $S_{2}=$ $80 \mathrm{~mm}$, the length of the connecting rod I was $S_{3}=140 \mathrm{~mm}$, the length of the connecting rod II was $S_{4}=260 \mathrm{~mm}$, the length of rod to connecting the rack was $S_{6}=314 \mathrm{~mm}$, and the height of planting track was $H=450 \mathrm{~mm}$. According to the above parameters and the control requirements of the duckbill mechanism, the cam stroke was determined to be $S=15 \mathrm{~mm}$. And the initial phase difference between the two cams was $180^{\circ}$. The experiment was carried out with pepper seedlings as transplanting objects. The results showed that when the planting frequency was $50-70$ plants/min, the seedling upright rate was $93 \%-91.1 \%$, the planting depth qualified rate was $96 \%-92 \%$. The leakage rate was $0-0.26 \%$, the variation coefficient of plant spacing was $0.37 \%-0.67 \%$, the injury rate was $0 \%$, and the mechanical damage degree of the mining surface was $2.43-3.77 \mathrm{~mm} / \mathrm{m}^{2}$. The machine can effectively improve the quality of transplanting, which can meet the production needs and design requirements of the mechanism.
\end{abstract}

Keywords: seedling transplanting, planting mechanism, digital speckle, parameter optimization, test analysis

DOI: $10.25165 /$ j.ijabe.20201301.5494

Citation: Jin X, Cheng Q, Zhao B, Ji J T, Li M Y. Design and test of 2ZYM-2 potted vegetable seedlings transplanting machine. Int J Agric \& Biol Eng, 2020; 13(1): 101-110.

\section{Introduction}

China is a big country in vegetable production and consumption. However, the planting and harvesting processes were mainly manual operations. It was difficult to guarantee the efficiency and quality of operation. At the same time, it reduced the comprehensive economic benefits of vegetable production and restricted the development of the vegetable industry ${ }^{[1-3]}$. The automatic transplanting machine had a complicated structure, high maintenance and use cost. Therefore, the mainstream dryland transplanting machine currently promoted and used in China was semi-automatic transplanting machine ${ }^{[4-6]}$. The tray seedling transplanting technology has many significant advantages such as enhancing the ability of seedlings to resist disasters and stress,

Received date: 2019-10-31 Accepted date: 2020-01-13

Biographies: Xin Jin, $\mathrm{PhD}$, Associate Professor, research interests: vegetable production mechanization, Email: jx.771@163.com; Qun Cheng, Master candidate, research interests: precision agriculture technology, Email: 18437923892@163.com; Bo Zhao, Researcher, research interests: variable-rate technology in precision agriculture, Email: zhaoboshi@126.com; Mingyong Li, $\mathrm{PhD}$ candidate, research interests: agricultural information and intelligent machine, Email: mingyonglee@163.com.

*Corresponding author: Jiangtao Ji, PhD, Associate Professor, research interests: agricultural utility robot technology, Henan University of Science and Technology, Luoyang 471003, China. Tel: +86-379-64877837, Email: jjt0907@163.com. improving vegetable quality and yield and significant economic benefits $^{[7]}$. Due to the lack of systematic research on seedling conditions, transplanting conditions and effects, the efficiency of dryland semi-automatic transplanting machines was still low. The quality of transplanting operations needs to be improved ${ }^{[8-10]}$. The planting mechanism is the core component of the semi-automatic transplanting machine, which directly affects many key indexes of the transplanting effect. According to the type of planter, it can be divided into clamp type, flexible disc type, hanging cup type, guide seed tube type, double conveyor belt type, slide branching wheel type and duckbill type. Therefore, it is necessary to optimize the design parameters and key components of vegetable transplanters on the basis of research on vegetable seedling conditions and transplanting effects ${ }^{[11-15]}$.

The working objects of the vegetable transplanter are the potted vegetable seedlings that have been cultivated through the tray. In the transplanting operation, workers smoothly took out the seedlings from the seedling tray, sequentially put them into the mechanism of transporting seedlings. They were then released into the seedling bucket. Finally, the seedlings were implanted into the field by the planter. The planting process requires low seedlings damage, accurate and orderly movement of various mechanisms. This was conducive to the survival of the seedlings after planting ${ }^{[16,17]}$. Foreign have begun to develop transplanting equipment earlier, and the technology was complete and mature. Various types of automatic transplanting machines have been 
developed. Typical examples were the German A821 planter, the Italian Aotema planter, the Japanese A-500 Kubota transplanter, the US DZCHC-DIP transplanter, the French Pearson dry field automatic transplanter, the Netherlands Model4000 transplanter, Finland RT-2 transplanter. However, these models still had problems such as complicated structure, low productivity, and high quality requirements for seedling cultivation ${ }^{[18-21]}$.

Domestic research on transplanting machinery started later. In order to improve the quality of transplanting operation, domestic scholars had done a lot of meaningful exploration and research on planting mechanism. For example, a planting mechanism of a planetary gear train-five-bar mechanism was designed, which can make the seedlings cover the soil in a static state ${ }^{[22]}$. A planetary wheel slide type planting mechanism was designed. The mechanism was completed by a combination of a planetary gear train and a slideway; the upright rate was $94 \%^{[23]}$. A five-bar planting mechanism was designed to achieve a large lift trajectory; the missing rate was $2.5 \%{ }^{[24]}$. A seedling planting device was designed; the movement of the cylinder was controlled by a solenoid valve to realize the clamping and release of the seedling. Its lodging rate was $21.9 \%{ }^{[25]}$. Combined with acupuncture and planting seedlings, a multi-rod seedling planting mechanism was designed. It can achieve zero-speed seedling, and the transplanting speed was $0.03 \mathrm{~m} / \mathrm{s}^{[26]}$. Faced with huge market demand, improving the efficiency and the quality of transplanting machines has become an urgent problem to be solved. To this end, this paper developed a semi-automatic potted vegetable seedlings transplant machine based on vegetable seedling conditions, seedling shape parameters and transplanting effect. Its key parameters and core components were designed. Finally, in order to verify the performance of the machine, it was tested in the field at different transplanting frequencies.

\section{Study of potted seedings characteristics}

A more typical pepper seedling was selected as the test subject for seedling. The variety of pepper seedlings was Honglong 13 . And the seedlings were cultivated at the Henan Modern Agricultural Research and Development Base. The seedlings were incubated with a 128 -well (16 rows $\times 8$ columns) seedling tray, as shown in Figure 1. The seedling tray was rectangular cone structure. The single hole size was $15 \mathrm{~mm} \times 15 \mathrm{~mm}$ for the upper, $30 \mathrm{~mm} \times 30 \mathrm{~mm}$ for the lower, $42 \mathrm{~mm}$ for the hole depth, and $21 \mathrm{~mL}$ for the hole volume. The main components of the carcass were charcoal, vermiculite and perlite. The volume ratio was charcoal: vermiculite: perlite $=3: 1: 2$. When the seedling age was $40 \mathrm{~d}$, the water content of the carcass was between $48.4 \%$ and $57.6 \%$. The pepper seedlings grew vigorously; the roots were developed and the carcass was fully wrapped.

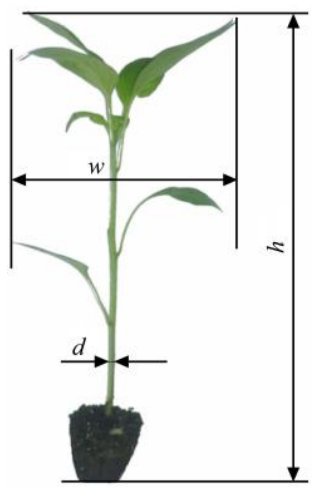

Figure 1 Test seedling
In order to provide theoretical reference for the design of the planting mechanism, 60 samples of pepper seedlings were selected and their related physical parameters were counted. The data are shown in Table 1. The $w$ is the broadening of the seedling leaves. $h$ is the height of the seedlings. $\quad w$ and $h$ were measured by a ruler with an accuracy of $1.0 \mathrm{~mm}$. $d$ is the diameter of the stem, measured from the side close to the carcass, using a vernier caliper with an accuracy of $0.05 \mathrm{~mm}$.

Table 1 Statistical results of pepper seedling characteristic parameters

\begin{tabular}{lccccc}
\hline \multicolumn{1}{c}{ Parameter } & Max & Min & Average & $\begin{array}{c}\text { Standard } \\
\text { deviation }\end{array}$ & $\begin{array}{c}\text { Coefficient } \\
\text { of variation }\end{array}$ \\
\hline Seedling leaf width $w / \mathrm{mm}$ & 105 & 78 & 87 & 9.00 & 0.10 \\
Seedling leaf height $h / \mathrm{mm}$ & 156 & 131 & 140 & 7.28 & 0.05 \\
Stem diameter $d / \mathrm{mm}$ & 2.85 & 2.30 & 2.60 & 0.22 & 0.08 \\
Weight/g & 19.7 & 17.3 & 18.5 & 0.93 & 0.05 \\
\hline
\end{tabular}

\section{Overall design of transplanter}

\subsection{Overall structural design}

2ZYM-2 potted vegetable seedlings transplanting machine was mainly composed of rotary disc type feeding mechanism, five-bar duckbill planting mechanism, power transmission mechanism, driving ground wheel, film laying device, earth covering device and frame assembly, etc. The structure diagram is shown in Figure 2. The seedling feeding mechanism was composed of transmission sprockets, spring diaphragm timing automatic feeding device and a rotary disc type feeding mechanism. It was installed
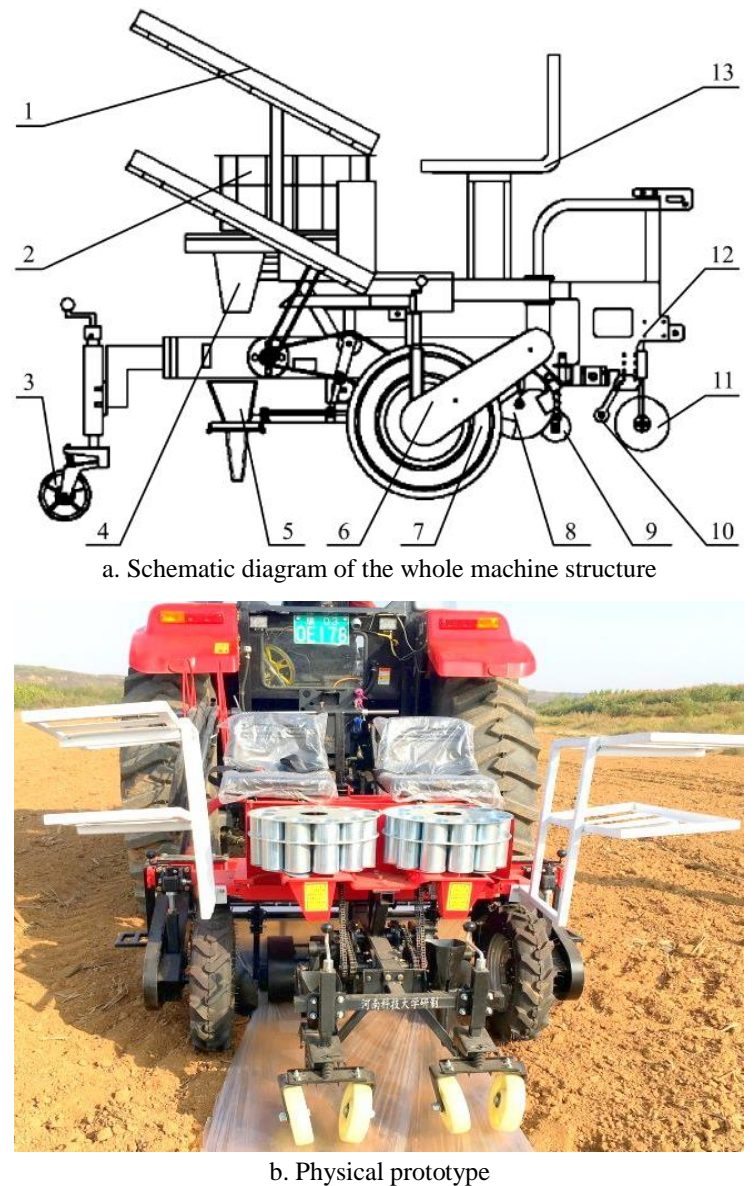

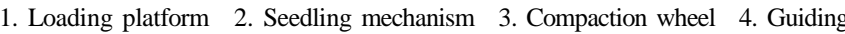
device 5. Planter 6. Transmission chain box 7. Driving wheel 8. Film overlaying soil device 9. Film pressing wheel 10. Film rollers 11. Ditcher assembly 12 . Frame assembly 13 . Seat

Figure 2 Structural sketch of the 2ZYM-2 transplanter 
in the upper part of the rack. The planting mechanism consisted of transmission sprockets, cranks, a cam, connecting rods, duckbill planters and the cable that controls the opening and closing of the duckbill. It was arranged on each side of the rack. The film laying device was composed of a film forming roller, film rolling wheels and the film covering device. It can retain the moisture in the soil after transplanting. The loading platform was mounted on both sides of the frame at an angle of $20^{\circ}$ to the horizontal. This facilitated the fixation of seedling trays and manual seedlings.

The main technical parameters of the transplanter are shown in Table 2.

Table 2 Main technical parameters

\begin{tabular}{lc}
\hline \multicolumn{1}{c}{ Items } & Parameter \\
\hline Structure type & Three-point suspension \\
Dimensions (length $\times$ width $\times$ height $) / \mathrm{mm}$ & $2240 \times 1520 \times 1650$ \\
Supporting power $/ \mathrm{kW}$ & $13.2-22.1$ \\
Mount type & Traction type \\
Machine quality $/ \mathrm{kg}$ & 420 \\
Working width $/ \mathrm{m}$ & $1-1.3$ \\
Number of job lines & 2 \\
Plant type & Duckbill \\
Work line spacing $/ \mathrm{cm}$ & 40 \\
Plant spacing $/ \mathrm{cm}$ & $30-50$ \\
Planting depth $/ \mathrm{cm}$ & $4-9$ \\
Working speed $/ \mathrm{mm} \cdot \mathrm{s}^{-1}$ & $150-550$ \\
Suitable seedling & $80-150 \mathrm{~mm}$ best \\
Working efficiency $/ \mathrm{hm}^{2} \cdot \mathrm{h}^{-1}$ & 0.19 \\
Number of operators $($ including tractor hand) & 3 \\
\hline
\end{tabular}

The design of the transplanting machine was 2 rows, which can realize automatic filming and planting operation. It was suitable for transplanting on flat land or ridge. The design line spacing was $40 \mathrm{~cm}$. And the plant spacing can be adjusted between 30$50 \mathrm{~cm}$. The plant spacing adjustment sprocket and its corresponding plant spacing are shown in Table 3.

Table 3 Plant spacing regulation table

\begin{tabular}{cccccc}
\hline Number of sprocket teeth & 54 & 50 & 47 & 42 & 38 \\
\hline Plant spacing/cm & 30 & 35 & 40 & 45 & 50 \\
\hline
\end{tabular}

\subsection{Working principle}

Potted vegetable seedlings were placed on the loading platforms on both sides before planting operation. Potted seedlings transplanting machines relied on tractors for traction operations. During the whole operation, the machine starts to lay the film when the machine walks, and stops the film when the machine stops. When the transplanter machine is driving, smoothly took out the seedlings from the seedling tray, sequentially put them into the mechanism of transporting seedlings. The seedling device was rotated with the seedling. When it rotates above the guide hole, the spring diaphragm opens automatically to release the seedling. Then close under the spring tension and hold the next seedling. The released seedlings were accurately placed above the spatial position of the planter through the guiding holes. At this time, the five-bar type duckbill mechanism moved to its highest position. Then the potted seedlings were accessed. When the duckbill mechanism carries the seedling to the lowest position, the cam zipper mechanism controls the duckbill mechanism to release the seedling for planting. The planting operation was then completed by the falling soil and the soil covering mechanism. When the planting mechanism moves away from the seedlings, the duckbill was closed and entered the next working cycle to achieve semi-automatic transplanting.

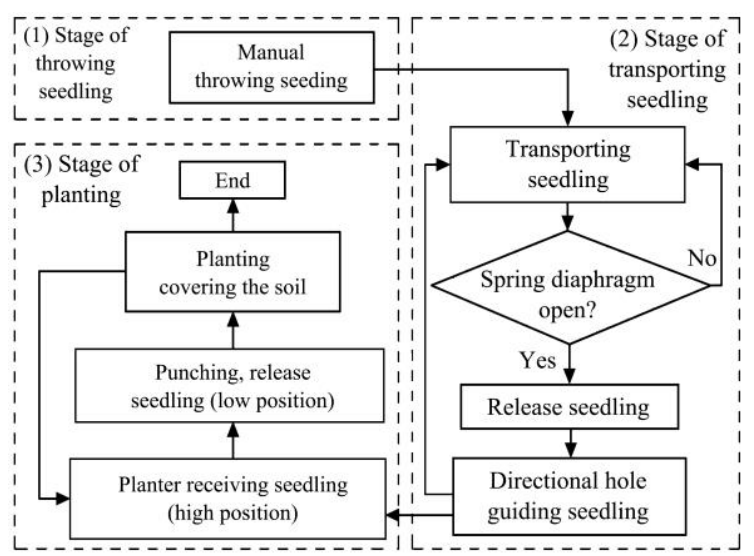

Figure 3 Working principle diagram of the transplanter

\subsection{Power layout}

The vegetable seedling transplanting machine used the tractor as the power source. Its power transmission system is shown in Figure 4. The tractor engine power was $13.2-22.1 \mathrm{~kW}$. The engine power was transmitted to the driving ground wheels on both sides of the transplanting machine via the running clutch. And it was transmitted from the ground wheel to the transplanter sprocket box. The main drive shaft of the transplanter connected the sprockets on both sides and the central drive system. While transmitting power, the rotational speed of the wheels on both sides of the transplanter was corrected. It ensures the accuracy of planting. The main drive shaft then connected the power to the side of the central drive train via the chain drive. The other end was connected to two sets of planting mechanisms, small gearboxes and seedlings transporting devices through a chain drive. It provides power for the planting mechanisms and the seedlings transporting devices, improving the fluency of the transplanter power transmission system.

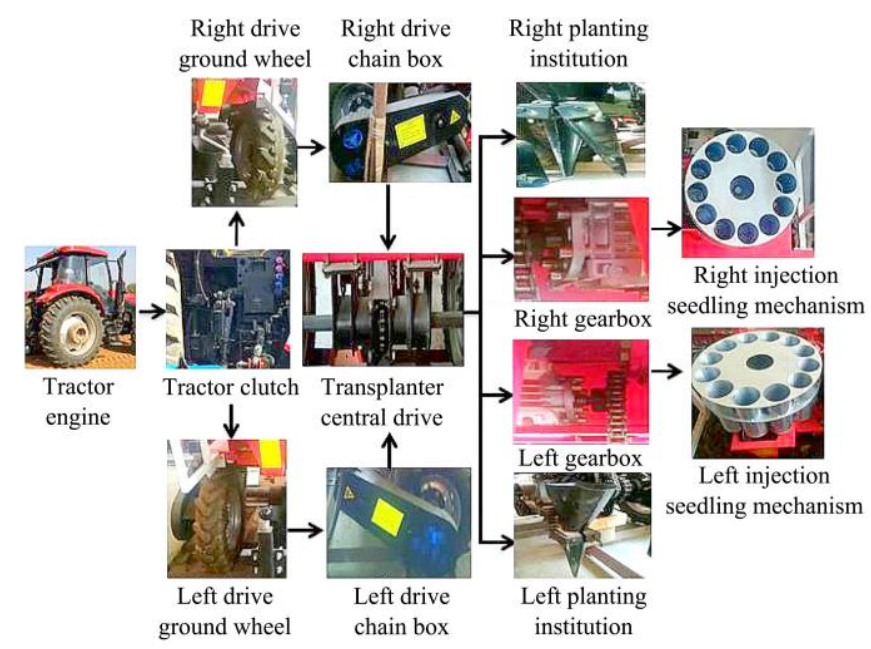

Figure 4 Power transmission system

\section{Design of key components}

The planting mechanism was the core component of the semi-automatic transplanting machine. Its performance directly determines the key indexes such as the upright rate, planting depth pass rate and other qualified indexes. Therefore, it is necessary to rationally design to improve the quality of transplanting operations.

\subsection{Requirements for planting mechanism design}

4.1.1 Trajectory of planter movement 
The vegetable seedling semi-automatic transplanting machine requires workers to feed the seedlings into the feeding mechanism. The seedlings were then released at specific locations, making the seedlings to fall accurately into the planter, so that the subsequent planting action goes smoothly. Then the feedling mechanism and the planting mechanism repeated the above actions. The movement process of the planter is shown in Figure 5. The planting mechanism was installed on the main beam of the rack through the hinges of two cranks. The height of the planting track and the planting depth can be adjusted by the tractor hydraulic adjustment device. Plant spacing can be adjusted by changing the plant spacing sprocket. The trajectory characteristics of the existing planting mechanisms were comprehensively compared. In order to achieve rapid and accurate planting operations, the design of the planter should meet the following requirements:

1) The theoretical design requires that the planting track has no dead point to ensure the smooth movement of the planter.

2) When the duckbill planter releases the seedlings and unearths, it should try to maintain a vertical attitude. This will prevent the duckbill planter from knocking down the seedlings or the injured seedlings. Otherwise, it will affect the effect of transplanting.

3) When the planter picking up the seedling at the highest point of its trajectory, the line speed of the planting point is zero. Achieving zero-speed seedlings picking can ensure that the seedlings are not damaged during this process. When the hole is punched at the lowest point of the trajectory, the line speed of the planting point is also zero. Achieving zero-speed seedlings releasing ensures the uprightness of transplanted seedlings.

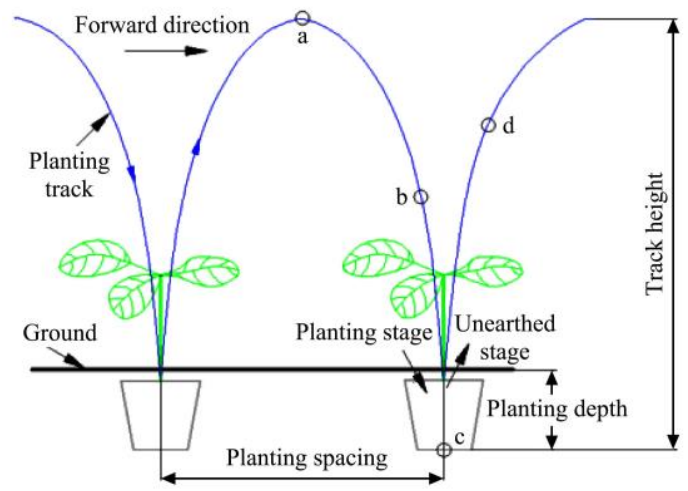

a. Dynamic trajectory of the planter

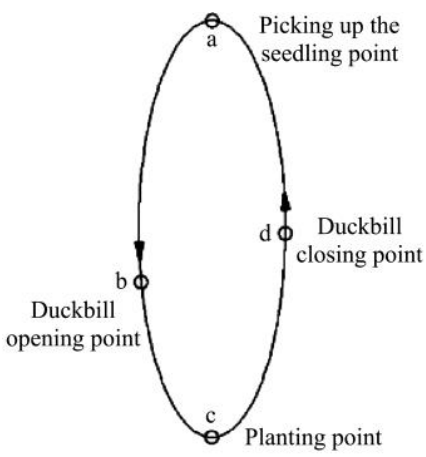

b. Static trajectory of the planter

Figure 5 Trajectory of planter movement

\subsubsection{State of cam motion}

The planter needs to be opened and closed in a timely manner, and the movement is smooth. This requires the cam to be at different stages of its contour when the planter makes different actions. Otherwise, it is easy to cause problems such as leakage, injury, and lodging. To this end, the requirements for the cam motion state are as follows:

1) The duckbill remains closed when the seedling was picked up at a high position. The contact line of the cam and the driven wheel was in the first stage of the contour line.

2) When the duckbill starts to open and punches, the contact line is in the second stage of the contour line.

3) When the duckbill is fully opened, the seedling is released and transplanted. At this time, the contact line is at the end of the second phase of the contour line, and the beginning of the third phase.

4) The planter completes the planting operation. When the duckbill begins to close, the contact line is in the fourth stage of the contour line.

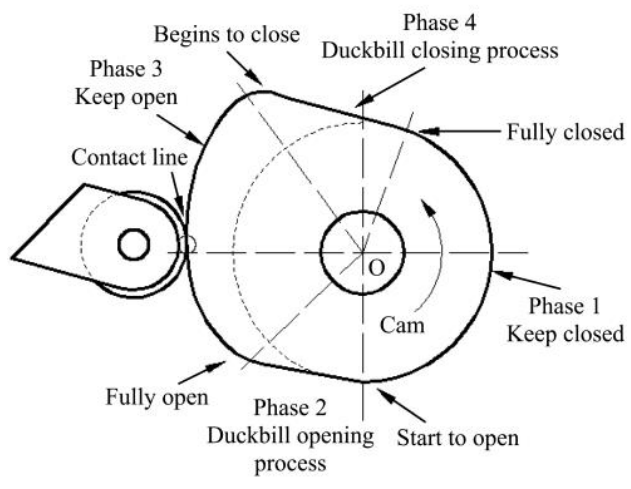

Figure 6 State of cam and duckbill movement

\subsection{Mechanism structure and working principle}

4.2.1 Structure and principle of planting mechanism

The machine adopted a five-bar type duckbill planting mechanism to transplant seedlings. Its structural form is shown in Figure 7. The mechanism was mainly composed of sprockets, crank, connecting rods, cam, duckbill type planter (seedlings picking device, duckbill mechanism, fixed connector, return springs), shift fork, pulley and cable. The ends of the two cranks were respectively concentrically and fixedly mounted with the sprocket at the position where they were located. The connections between the crank and the connecting rods were all hinged. The other end of the connecting rod II was welded to the seedlings picking device. The cam and the crank II were concentric and fixedly mounted. One end of the shift fork was hinged with the connecting rod II, and the other end was fixedly installed with the cable. One end of the fixed connector was fixedly installed with the cable around the pulley, and the other end was welded to the upper part of the duckbill. The two duckbills were respectively hinged to the seedlings picking device through the connecting piece. Both ends of the return spring were hooked to the two connecting pieces. The opening and closing of the duckbill mechanism was achieved by different motion states of the cam.

During operation, the power of the planting mechanism was transmitted by the central drive system. The two sprocket wheels drive the crank I and crank II simultaneously to make a clockwise uniform circular motion. The crank II acted directly on the cam and the link II to drive the duckbill control mechanism to work. The specific process was as follows: When the seedling falls from the guiding hole, the cam reaches its maximum stroke. The shift fork rotates clockwise and its swing angle was maximized to tension the cable. The fixed connector rotates clockwise to overcome the spring tension. Thereby the duckbill was opened (putting seedlings, planting). Correspondingly, when the cam moves to its lowest stroke, the driven wheel mechanism rotated 
counterclockwise to loosen the cable. Together with the return tension of the spring, the fixed connector was rotated counterclockwise to reset. Thereby the duckbill mechanism was closed. The planting mechanism kept the closed state and continued to move (to pick up the seedlings and transport). Then loop the job like this.

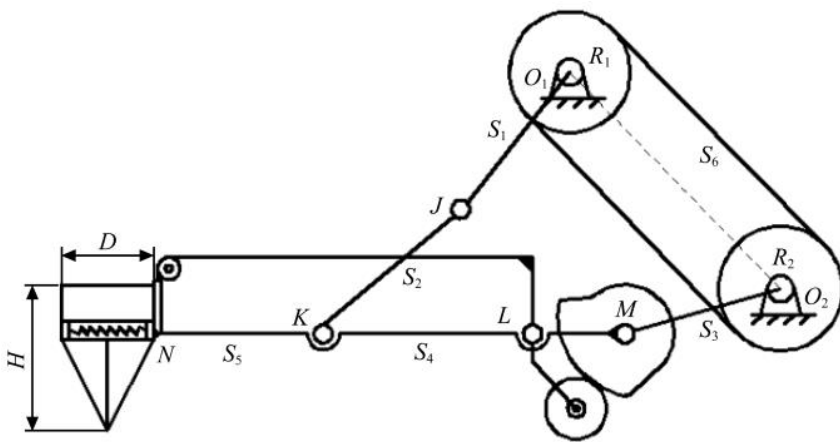

a. Structure diagram of the planting mechanism

Note: Points $N$ and $M$ were solder joints. Point $P$ was the fixed point of the shift fork and the cable; $R_{1}$ was the drive sprocket radius of the crank I; $R_{2}$ was the drive sprocket radius of the crank II; $S_{1}$ was the length of the crank I; $S_{2}$ was the length of the link I; $S_{3}$ was the length of the crank II; $S_{4}$ was the length of the link II; $S_{5}$ was the length of the hinge point of the links I and II to the duckbill; $S_{6}$ was the length of the rod that connects the rack.

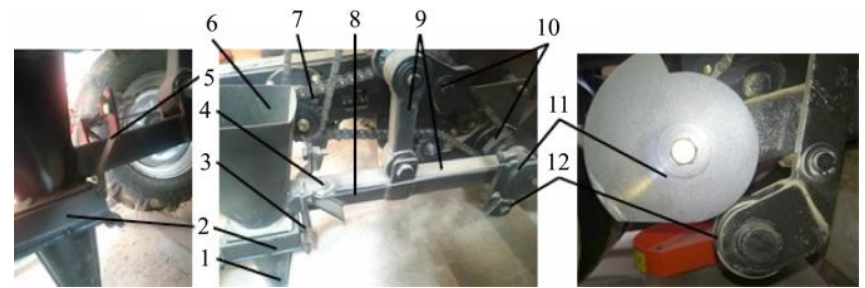

b. Physical structure of the planting mechanism

1. Duckbill mechanism 2. Connector 3. Reset spring 4. Pulley 5. Fixed connector 6. Seedling tube 7. Sprocket 8. Cable 9. Connecting rod 10. Crank 11. Cam 12. Fork

Figure 7 Five-bar type duckbill planting mechanism

\subsubsection{Cam structure and working principle}

The design adopted the disc cam to control the opening and closing state of the planter. Thereby motions of seedlings picking, putting seedlings and planting can be realized. Its structural form is shown in Figure 8. The cam was composed of a near-rest angle phase, a push motion angle phase, a far-away angle phase, and a return motion angle phase, which in turn correspond to $\angle 1, \angle 2, \angle 3$, $\angle 4$. The cam was mounted concentrically with the end of the connecting rod II. The lower end of the shift fork was hinged to the connecting rod II. The upper end was fixedly mounted with the cable. The roller of the fork was in line contact with the cam.

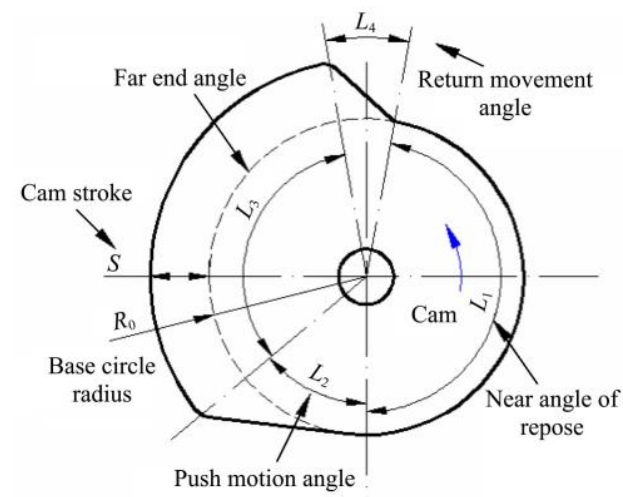

Figure 8 Cam structure diagram

During operation, the power was transmitted by the crank II. The two cams rotated in the same direction as the ground wheel.

Due to the initial installation phase difference, the state of the duckbill mechanism controlled by the two cams was different in the stationary state. Specifically, one was open and the other was closed. Taking the initial state as closed example, when the contact line between the cam and the driven wheel is in the $\angle 1$ stage, the shift fork is in the home position, and the cable is slack. The duckbill planter was closed under the action of return springs. This can ensure that the planter does not leak seedlings. When the cam continues to move to the $\angle 2$ stage, the cable tensioning force gradually increases to be greater than the preload of the spring. The duckbill began to open for a hole punching job. While the cam moves to the $\angle 3$ stage, the radial diameter of the cam increases to the maximum. The swing angle of the fork reached the limit position and the displacement of the cable reaches the maximum. The opening angle of the duckbill was maximized. At this stage, the planter puts seedlings and planting operations. When the cam moves to the $\angle 4$ stage, the radial diameter of the cam decreases sharply. The cable quickly became slack. The duckbill was reset and closed under the action of the spring preload, and the shift fork was reset. Then repeat this action process.

\section{Key parameter design of core components}

\subsection{Parameter design of planting mechanism}

The planting mechanism is a five-bar type. Its core components are crank 1 , crank 2 , connecting rod 1 , connecting rod 2 and connecting rod. In order to obtain the optimal parameters of the core components, a simplified and adjustable parameter planting mechanism was first produced. The parameters were then tested and optimized using digital speckle techniques. The test device is shown in Figure 9.

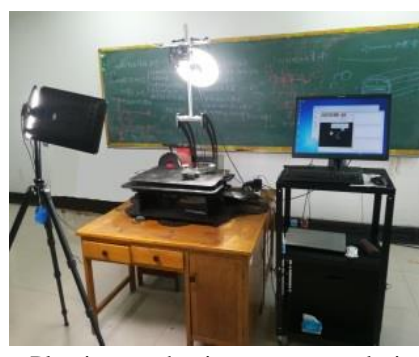

a. Planting mechanism parameter design $\mathrm{b}$. Simplified five-bar duckbill planting test bench

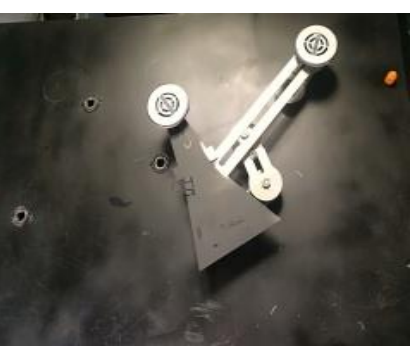

Figure 9 Test bench for parameter design

During the test, adjust the length of the crank and connecting rod to the set value. The two drive shafts are further rotated at a constant speed to drive the five-bar mechanism. Adjust the lengths of the crank and the connecting rod to different values to obtain their motion data. The motion characteristics were analyzed by digital speckle technique.

After a large number of experiments, the optimal combination of planting mechanism was determined as follows: $R_{1}=45 \mathrm{~mm}$, $S_{1}=100 \mathrm{~mm}, S_{2}=80 \mathrm{~mm}, S_{3}=140 \mathrm{~mm}, S_{4}=260 \mathrm{~mm}, S_{5}=100 \mathrm{~mm}$, $S_{6}=180 \mathrm{~mm}$. The planting track height was $450 \mathrm{~mm}$. Under this condition, the motion characteristics of the planter are shown in Figure 10.

Point $a$ was the seeding picking point. At this time, the speed was zero and it had a certain acceleration. Point $b$ was the opening point of the duckbill. It had a certain speed. But its acceleration was close to zero. Point $c$ was the seedlings putting point. Its speed was zero and the acceleration was very large. Point $d$ was the duckbill closing point. Its speed was increasing and the acceleration was drastically reduced. The rationality of the optimal parameter combination was verified. 


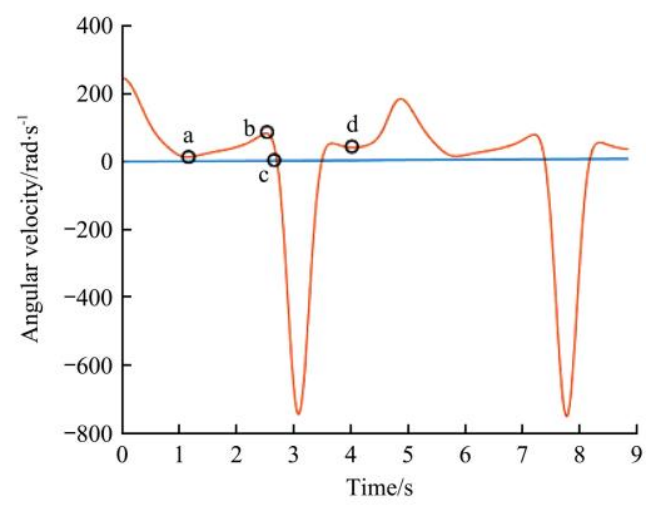

a. Analysis of the speed curve of planter

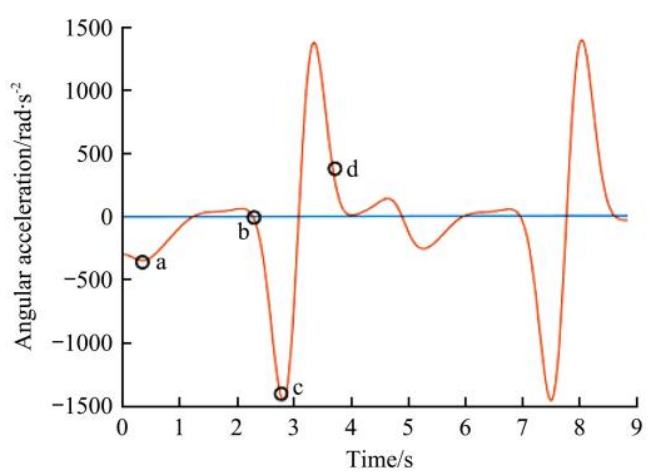

b. Analysis of the acceleration curve of planter

Figure 10 Analysis of the motion characteristics of the planter

\subsection{Parameter design of duckbill mechanism}

The planter is the core component of the planting mechanism. Reliable planters can improve the quality of work and lay the foundation for stable crop production and high yield. The planter was a duckbill type, which mainly includes seedlings picking device, connecting pieces, spring pull rods, duckbill mechanism, return springs and fixed connector. The duckbill planter was hingedly mounted with the seedlings picking device. It opens and closes in a timely manner and performs the functions of punching, picking seedlings and planting.

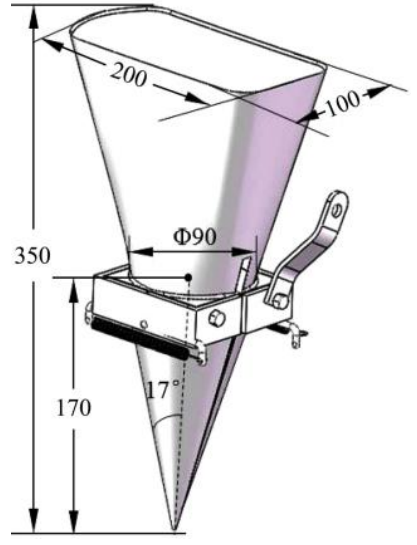

a. Three-dimensional model of duckbill mechanism

Figure 11 Duckbill mechanism design

Design requirements of duckbill mechanism:

1) Between the end of planting and the next seedling picking, the duckbill mechanism should be kept closed so that the next seedling can be taken.

2) The duckbill needs to meet the opening angle of $25^{\circ}$. That is to say, the angle of the duckbill change from the closed state to the open state is $25^{\circ}$. This ensures that the angle of the duckbill is open properly.
3) The movement of the duckbill does not interfere with the seedling.

According to the physical parameters of the seedlings, the parameters of the duckbill mechanism were designed as follows: the upper opening diameter $D=90 \mathrm{~mm}$. The height was $H=$ $170 \mathrm{~mm}$. The duckbill cone angle was $17^{\circ}$. The upper opening of the seedling picking device had a size of $200 \mathrm{~mm} \times 100 \mathrm{~mm}$. The lower opening had a diameter of $\Phi 90$. According to the design requirements, the length of the fixed connector was determined to be $L=83 \mathrm{~mm}$ and the width $T=28 \mathrm{~mm}$.

\subsection{Parameter design of cam and shift fork}

The cam rotated coaxially with the link II. Its function was to drive the shift fork to swing through the change of the contour line. Thereby, the planter can be in the corresponding state in all phases of transplanting. The movement of the cam and the shift fork between the two extreme positions is shown in Figure 12.

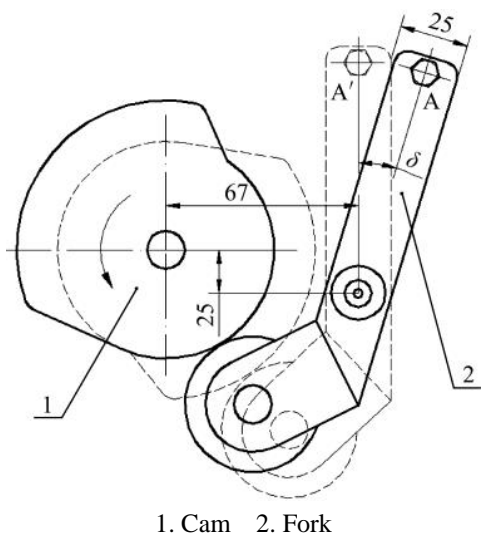

Figure 12 Limit positions of cam and shift fork

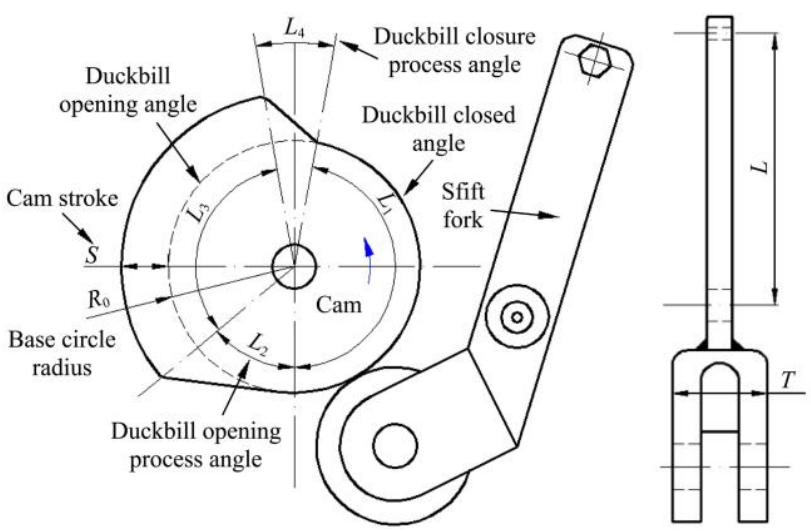

Figure 13 Cam and shift fork parameter design

Design requirements for cams and shift forks:

1) The seedlings picking device can pick up the seedlings at a high position. It can also carry out putting seedlings and planting operations in the low position.

2) The shift fork must have a $25 \mathrm{~mm}$ telescopic space. That is, during the movement of the shift fork from the $A$ position to the $A^{\prime}$ position, the displacement of the shift fork is $25 \mathrm{~mm}$ in the direction of the cable. This will ensure that the angle of the duckbill opening is appropriate. The two extreme positions are shown in Figure 10.

3) The shift fork and the connecting rod do not interfere during the movement.

4) The horizontal and vertical distance between the center of the cam and the shift fork is required to be $67 \mathrm{~mm}$ and $25 \mathrm{~mm}$. The angle between the two extreme positions of the shift fork (from the A position to the $\mathrm{A}^{\prime}$ position) is $\delta=17^{\circ}$. 
5) The cam mechanism on both sides of the transplanter has a certain initial installation phase difference. This facilitates intermittent punching and planting operations on both sides of the transplanting machine.

According to the design requirements, the length of the shift fork was determined to be $L=85 \mathrm{~mm}$ and the width was $T=30 \mathrm{~mm}$. When the cam moves to the $\angle 1$ stage, the seedlings picking device is used to pick up the seedlings. When it moves to the $\angle 2$ stage, the duckbill performs a punching operation. When it moves to the end of the $\angle 2$ stage, the planter quickly releases the seedlings. When it moves to the Stage 3, the duckbill mechanism quickly completes the planting operation. Planting is completed in the $\angle 4$ stage. The shift fork is reset by the spring. The planter remains closed until the $\angle 1$ phase begins to cycle above. It was determined that $\angle 1=170^{\circ}, \angle 2=50^{\circ}, \angle 3=120^{\circ}, \angle 4=20^{\circ}$. The design determined that the cam base circle radius was $R_{0}=40 \mathrm{~mm}$, and the cam effective stroke was $S=15 \mathrm{~mm}$. The initial phase difference between the two cams was $\psi=180^{\circ}$.

\section{Field test}

\subsection{Test conditions}

In order to verify the quality of the semi-automatic transplanting device used for transplanting potted vegetable seedlings, an outdoor field trial was conducted. The outdoor field test conditions were the outdoor temperature of $23^{\circ} \mathrm{C}$, the air humidity of $27 \%$, the wind speed of $3.5 \mathrm{~m} / \mathrm{s}$, and the soil moisture content of about $12.5 \%$.

Requirements for the test site: The soil in the test field should be sand and the terrain is flat. The land needs to be turned over and shredded without weeds, straw or debris. Field planting performance tests were conducted in Yibin District, Luoyang City, Henan Province. The transplanting test site is shown in Figure 14.

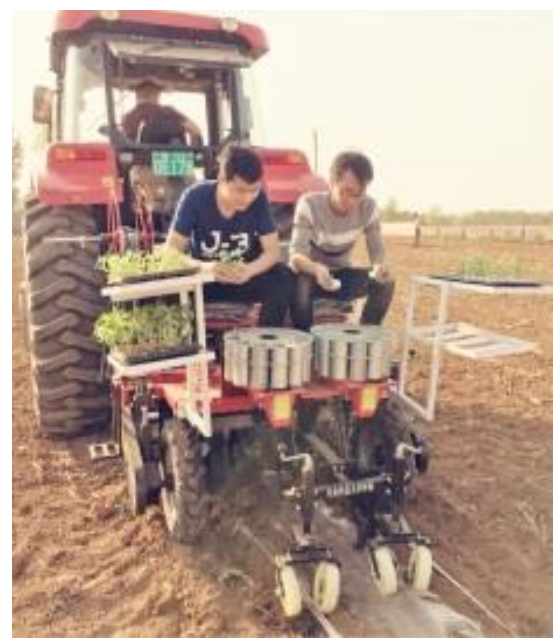

Figure 14 Transplanting test site

\subsection{Test materials and instruments}

The pepper seedling variety was Honglong 13. And the seedlings were cultivated by the 128 -hole seedling tray. The work of cultivating seedlings was completed at Henan Modern Agricultural Research and Development Base. The main components of the steroid matrix were peat, vermiculite and perlite. Its volume ratio was $3: 1: 2$. The carcass moisture content was between $48.4 \%$ and $57.6 \%$.

The test tractor was a Boma-424 type, equipped with an independent agricultural implement clamping suspension mechanism. The measuring instruments used in the test included scale, multi-angler, electro-optical digital tachometer, soil moisture meter and electronic stopwatch. The specific parameters are shown in Table 4.

Table 4 Test instrument

\begin{tabular}{ccccc}
\hline Items & Type & $\begin{array}{c}\text { Measuring } \\
\text { range }\end{array}$ & Accuracy & Quantity \\
\hline $\begin{array}{c}\text { Soil moisture } \\
\text { tester }\end{array}$ & Jakes TR-6 & $\begin{array}{c}-40-80^{\circ} \mathrm{C} \\
0-100 \%\end{array}$ & $\pm 0.3^{\circ} \mathrm{C} \pm 2 \%$ & 1 \\
$\begin{array}{c}\text { Multifunction } \\
\text { protractor }\end{array}$ & $\begin{array}{c}\text { WD digital angle } \\
\text { ruler }\end{array}$ & $0-360^{\circ}$ & $0.01^{\circ}$ & 1 \\
$\begin{array}{c}\text { SHIMPO } \\
\text { Dital tachometer }\end{array}$ & $\begin{array}{c}0.1-25000 \\
\text { DT-107A }\end{array}$ & $0.01 \mathrm{r} / \mathrm{min}$ & 1 \\
$\begin{array}{c}\text { Electronic } \\
\text { stopwatch }\end{array}$ & YS-810 & $0-10 \mathrm{~h}-\mathrm{m}^{\circ}$ & $0.01 \mathrm{~s}$ & 1 \\
Scale & Deli scale & $0-30 \mathrm{~cm}$ & $1 \mathrm{~mm}$ & 1 \\
Tape measure & $\begin{array}{c}\text { Casilo portable } \\
\text { steel tape measure }\end{array}$ & $0-100 \mathrm{~m}$ & $1 \mathrm{~mm}$ & 1 \\
Benchmark & ZX-8008 & - & - & $\begin{array}{c}\text { a certain } \\
\text { amount }\end{array}$ \\
\hline
\end{tabular}

\subsection{Test indexes}

Planting depth qualified rate and plant spacing coefficient of variation were important evaluation indexes of transplanting accuracy. Seedlings upright rate, leakage rate, injury rate of seedlings, and mechanical damage degree of the mulching film surface were the evaluation indexes of transplanting machine performance. The specific calculation formulas are as follows:

$$
\begin{gathered}
H=\frac{N_{h}}{N} \times 100 \% \\
L=\left(1-\frac{N_{D F}}{N}\right) \times 100 \% \\
M=\frac{N_{L Z}}{N} \times 100 \% \\
W=\frac{N_{S M}}{N} \times 100 \% \\
C V_{x}=\frac{S_{x}}{\bar{X}} \times 100 \% \\
S_{p}=\frac{1000 \sum_{i=1}^{n_{p}} l_{i}}{L \cdot B}
\end{gathered}
$$

where, $H$ is the planting depth qualified rate, $\% ; L$ is the seedlings upright rate, $\% ; M$ is the leakage rate, $\% ; W$ is the injury rate of seedlings, $\% ; C V_{x}$ is the variation coefficient of the plant spacing, $\%$; $S p$ is the mechanical damage degree of the mining surface, $\mathrm{mm} / \mathrm{m}^{2}$; $N_{h}$ is the number of seedlings with good planting depth; $N_{D F}$ is the number of lodging plants; $N_{L Z}$ is the number of plants lost; $N_{S M}$ is the number of injured plants; $S_{x}$ is the standard deviation of the plant spacing; $\bar{X}$ is the average of the plant spacing; $N$ is the total number of seedlings; $L_{i}$ is the side length of the mechanically damaged part at the $i^{\text {th }}$ position in the measurement area, $\mathrm{mm} ; L$ is the length of the measurement area, $\mathrm{m} ; B$ is the average width of the film's lighting surface, $\mathrm{mm} ; n_{p}$ is the number of measuring points.

The higher the planting depth qualified rate and Seedlings upright rate, the better. The remaining indexes were as low as possible.

\subsection{Test method}

Before the test, the condition of the transplanter should be strictly checked to ensure that it was in good condition. Thereby avoiding the performance degradation of the machine and affecting the test results. At the same time, adjust the working parameters of each mechanism as follows. Adjust the transplanting rack 
parallel to the ground. Adjust the depth of the opener to $10 \mathrm{~cm}$. The angle and depth of the earth-reducing wheel were adjusted to $\pm 12^{\circ}$ and $6 \mathrm{~cm}$ by the spiral fine adjustment rod. A 54-tooth sprocket was used to obtain a theoretical plant spacing of $30 \mathrm{~cm}$. The planting depth was adjusted to $8 \mathrm{~cm}$ by adjusting the position of the main beam.

Then, the potted seedlings were placed on the loading platform. The $20 \mathrm{~mm}$ high side rails uniformly distributed around it can effectively fix the seedling tray. In order to obtain the desired working speed, the ground speed of the transplanter was measured by a digital tachometer. Adjust the speed of the transplanter to $250 \mathrm{~mm} / \mathrm{s}, 350 \mathrm{~mm} / \mathrm{s}$ and $450 \mathrm{~mm} / \mathrm{s}$, respectively. The corresponding planting frequency was 50 plants $/ \mathrm{min}, 70$ plants $/ \mathrm{min}$, and 90 plants/min. After that, the seedlings were taken manually and fed into the seedlings feeding mechanism.
In order to ensure the accuracy of the test results, it was necessary to wait for the machine to run at a stable speed before testing. 11 trays of potted seedlings ( 2 trays of spare) were selected for testing. Moreover, the 12 seedlings of the transplanter near the start and stop stages were not included in the statistics. Take $20 \mathrm{~m}$ as a measurement area and set a benchmark. Three measurement zones were taken at each planting frequency. And the measurement zone cannot be repeated. Three groups of experiments were performed at each planting frequency, a total of 9 groups. Each time when 128 seedlings were transplanted, the test data was recorded and brought into the above formula for statistics.

\section{Results and discussion}

\subsection{Test results}

The test results are shown in Table 5 .

Table 5 Test results of main performance indexes

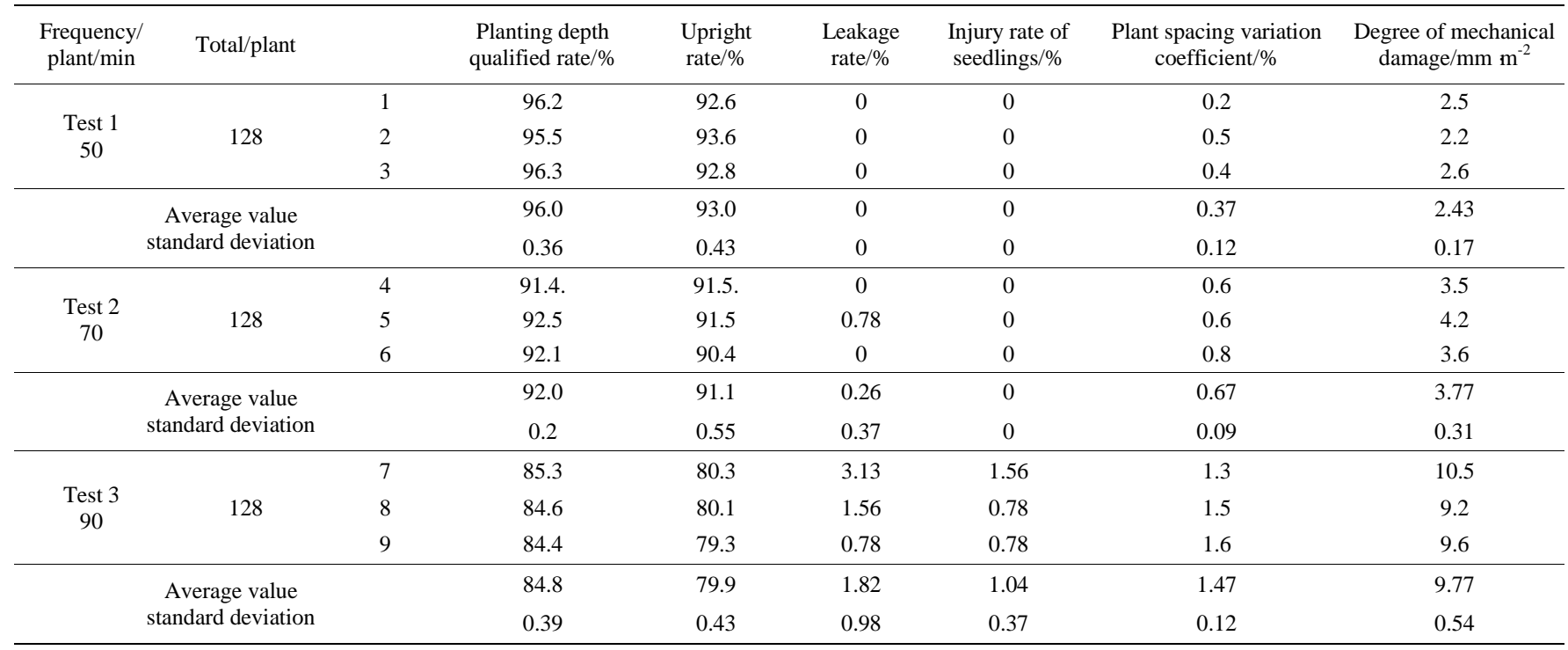

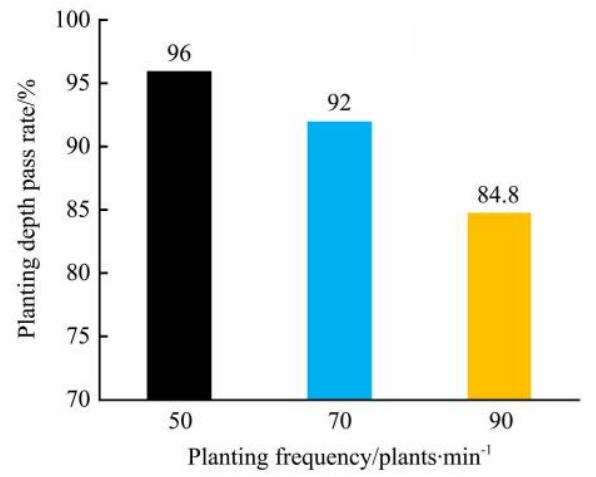

a.

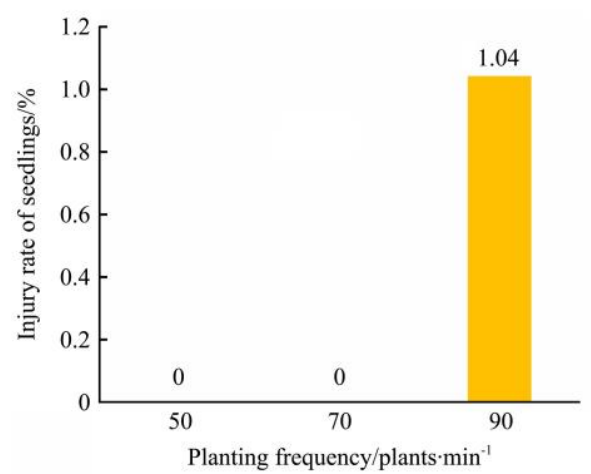

d.

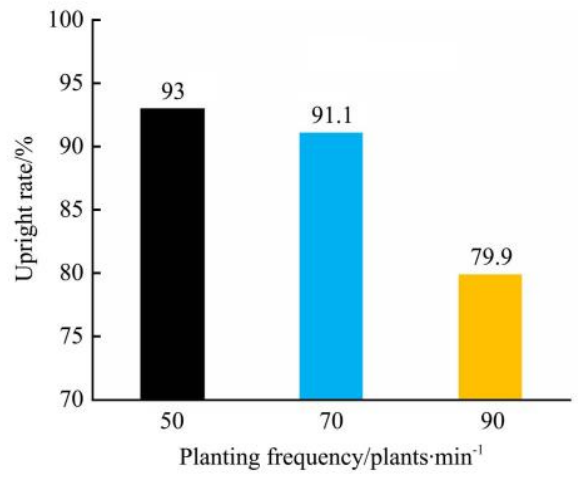

b.

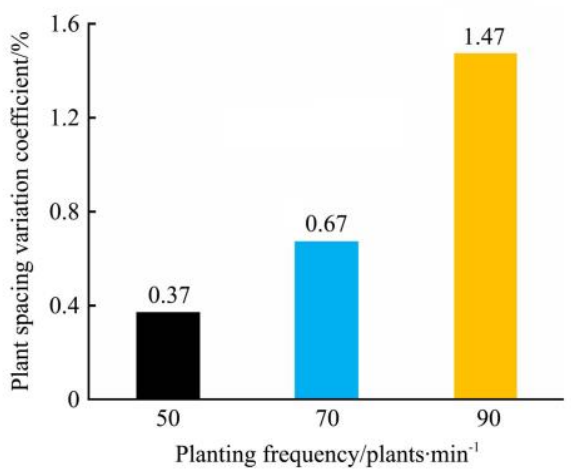

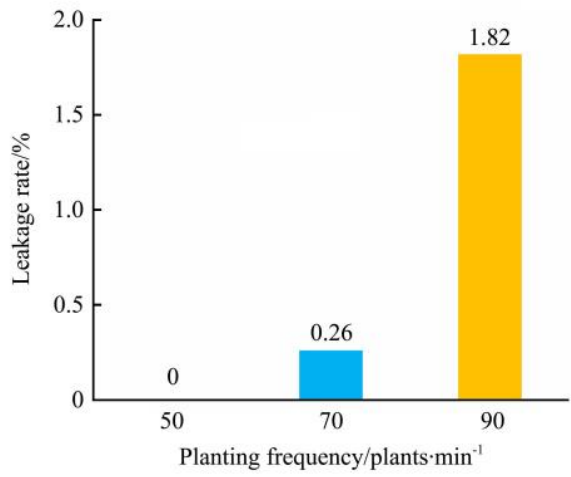

c.

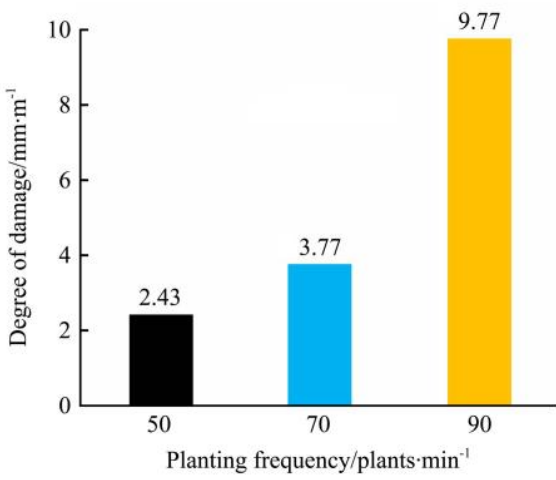

Figure 15 Average of test indexes at different planting frequencies 
It can be seen from the observation of the test process and the test data of Table 5 that the components of the vegetable transplanter operate smoothly. The machine can better meet the requirements of potted vegetable seedlings transplanting operation. The test results showed that under the test conditions, the planting depth qualified rate and upright rate reached the highest at 50 plants/min, which were $96 \%$ and $93 \%$ respectively, it was the lowest at 90 plants/min, which were $84.8 \%$ and $79.9 \%$, respectively. The rate of missing planting, the variation coefficient of plant spacing and the degree of mechanical damage of the lighting surface reached the lowest at 50 plants/min, which were $0,0.37 \%$ and $2.43 \mathrm{~mm} / \mathrm{m}^{2}$. At the same time, it was the highest at 90 plants/min, which were $1.82 \%, 1.47 \%$, and $9.77 \mathrm{~mm} / \mathrm{m}^{2}$, respectively. The injury rate increased from 0 to $1.04 \%$ after the planting frequency increased to 90 plants/min. This result showed that the machine meets the design requirements of semi-automatic transplanters.

With the increase of transplanting frequency, the planting depth qualified rate and upright rate showed a downward trend. The leakage rate, the coefficient of variation of plant spacing and the degree of mechanical damage of the lighting surface showed an upward trend. Especially when the transplanting frequency was increased from 70 plants/min to 90 plants/min, the planting depth qualified rate and seedlings upright rate decreased greatly. At the same time, the injury rate, leakage rate, the variation coefficient of plant spacing and the mechanical damage degree of the lighting surface increased greatly.

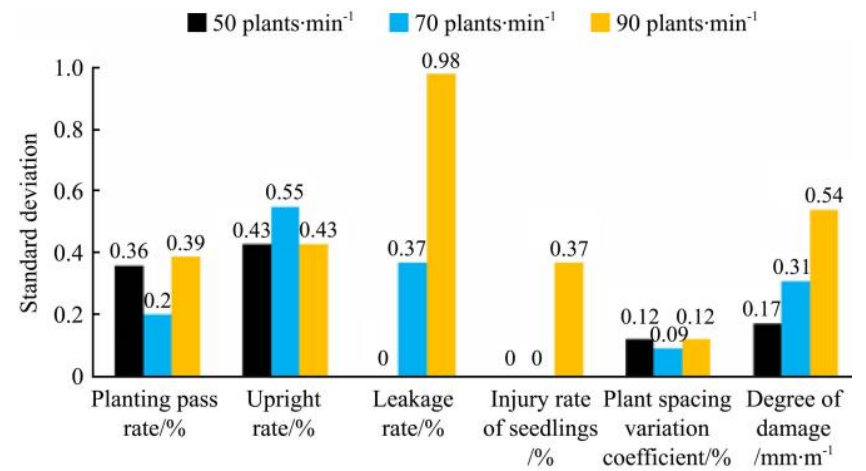

Figure 16 Standard deviation of test indexes at different planting frequencies

The standard deviation of the indexes ranges from 0 to 0.98 . The operation of this machine was stable and reliable.

\subsection{Discussion}

The planting mechanism was the core component of the semi-automatic transplanting machine and was also a difficult point in design. In this study, five-bar duckbill planting mechanism, disc cam and forks were used to achieve accurate release and planting of seedlings. In this study, five-bar duckbill planting mechanism, disc cam and shift fork were used to achieve accurate release and planting of seedlings. The chain drive was used to realize the feeding of the seedling tray. It can be seen from the test that the designed transfer device can meet the requirements of the transplanting operation. When the transplanting frequency was 50 plants $/ \mathrm{min}$ to 70 plants/min, the operation effect was better. However, when the frequency of transplanting was too high, especially over 90 plants/min, the transplanting effect was significantly reduced. The main reasons for this problem are as follows:

(1) When the frequency of transplanting increased, the corresponding work speed increased. The speed and acceleration of the planting mechanism increased accordingly. This tended to increase the collision strength between the seedling and the seedlings picking device. Therefore, the spatial movement posture of the seedlings was changed or the carcass was broken. These were easy to cause seedling lodging, seedling damage, and plant spacing change, and therefore reducing the transplanting effect.

(2) As the frequency of transplanting increased, the time it took for the planter to open and close was reduced. The horizontal speed when the seedlings were released was excessive. This also increased the kinetic energy of the planter when it was punched, resulting in insufficient soil backflow. These lead to the lodging of seedlings, the reduction of planting depth, affecting the planting effect.

(3) When the frequency of transplanting increased, the rotational inertia of the slewing mechanism in the planting mechanism was excessive. When the seedlings fall from the guiding hole, they cannot enter the seedlings picking device smoothly. The generated shaking caused displacement or damage of the seedlings, reducing the transplanting effect.

(4) When the frequency of transplanting increased, the speed at which workers released seedlings was correspondingly accelerated. High-speed operation was easy to cause artificial fatigue, resulting in inaccurate seedlings putting time and spatial position. It affected the cooperation between various mechanisms and reduced the transplanting effect.

(5) The wind speed was too large during the test, which has a certain negative effect on the transplanting effect.

For the above reasons, some measures can be taken to further improve the high-speed performance of the semi-automatic transplanting device through improving the structure of the planting mechanism through optimization and the planting trajectory curve and parameters. At the same time, a spring or balance block can be added to the mechanism where the inertia of the mechanism was large. And other measures can be taken to reduce the inertial force to guarantee the quality of transplanting. The planter of the transplanter can be made into a closed structure, which helps to improve the planting effect.

However, the test object type was single, only pepper seedlings were chosen for multiple experiments that lack of comprehensive research on the characteristics of various vegetable seedlings. Vegetable varieties can be added and the machine requires multiple sets of controlled trials to verify its performance.

\section{Conclusions}

(1) A semi-automatic potted vegetable seedlings transplanting machine was designed. The operation of taking seedlings and feeding seedlings was done manually. The rotary disc type mechanism was used to complete the seedlings transporting. The five-bar duckbill mechanism completed the seedlings picking and planting. The planter was controlled by a cam-cable mechanism. It can ensure that the timing of opening and closing was appropriate and the movement of each component was fluent.

(2) Through the analysis of the planting operation process, the key parameters of the planting mechanism and the plant control mechanism were determined. In order to meet the position and action requirements of picking and putting seedlings, at the same time, the impact should be as small as possible, the key structure and working parameters of the cam and the shift fork were determined. The details were as follows: the shift fork height $H=50 \mathrm{~mm}$, width $B=35 \mathrm{~mm}$. The base circle radius of the disc cam was $R_{0}=40 \mathrm{~mm}$, and the effective stroke $S=15 \mathrm{~mm}$. The 
upper opening diameter of duckbill mechanism was $D=90 \mathrm{~mm}$. The height of the duckbill was $H=170 \mathrm{~mm}$. The taper angle of the duckbill was $17^{\circ}$. The maximum angle of the duckbill opening was $25^{\circ}$.

(3) The whole machine test results showed that when the transplanting frequency was 50-70 plants/min, the planting depth qualified rate was $96.0 \%-92.0 \%$, the upright rate was $93.0 \%-91.1 \%$, the leakage rate was $0-0.26 \%$, the injury rate was 0 , the variation coefficient of plant spacing was $0.37 \%-0.67 \%$, and the mechanical damage degree of the mining surface was $23.4-33.7 \mathrm{~mm} / \mathrm{m}^{2}$.

\section{Acknowledgements}

The work was sponsored by the National Key Research and Development Program of China Project (No.2016YFD0700100), the National Natural Science Foundation of China (No.51975186), the Key Research and Development Program of Guangdong Province (No.2019B020222004), and the Innovation Scientists and Technicians Talent Projects of Henan Provincial Department of Education (No.19HASTIT021)

\section{[References]}

[1] Liu J D, Cao W B, Tian D Y, Tang H Y, Zhao H Z. Kinematic analysis and experiment of planetary five-bar planting mechanism for zero-speed transplanting on mulch film. International Journal of Agricultural and Biological Engineering, 2016; 9(4): 84-91.

[2] Jin X, Du X W, Geng G S, Ji J T, Dong X, Liu W X. Experiment on planting system of 2ZDJ-2 seedling transplanting machine. Transactions of the CSAM, 2015; 46(12): 26-31. (in Chinese)

[3] Cui C H, Chen Z B, Xu D F, Yang X M, Fu Y G. Research status and development trend of whole-row plug seedling transplanting machine. Xinjiang Agricultural Mechanization, 2019; 4: 20-23. (in Chinese)

[4] Chen D J, Hou J L, Shi G Y, Li T H, Zhang Y S, Chang J M. Analysis of the current status of domestic dryland transplanter technology. Chinese Journal of Agricultural Mechanization, 2018; 39(7): 98-102. (in Chinese).

[5] Du X W, Li C, Li M Y, Yang L H, Jin X, Ji J T. Advances in the research of automatic seedlings for transplanting seedlings in dry farming. Agricultural Mechanization Research, 2018; 40(8): 263-268. (in Chinese)

[6] Liu M, Zhang M, Xu Y, Liu W, Zhang X M. Kinematics analysis and experiment of planting mechanism of 2ZBZ-2A transplanter. Journal of Agricultural Mechanization Research, 2015; 37(11): 31-36. (in Chinese)

[7] Liu C X, Li X H, Yue X M, Zhao H Y. Current status and development trend of dryland transplanting machines in China. Journal of Agricultural Mechanization Research, 2012; 34(11): 249-252. (in Chinese)

[8] Jin, X, Li D Y, Ma H, Ji J T, Zhao K X, Pang, J. Development of single row automatic transplanting device for potted vegetable seedlings. Int $\mathbf{J}$ Agric \& Biol Eng, 2018; 11(3): 67-75.

[9] Ye B L, Yi W M, Yu G H, Gao Y, Zhao X. Optimization design and test of rice plug seedling transplanting mechanism of planetary gear train with incomplete eccentric circular gear and non-circular gears. Int J Agric \& Biol Eng, 2017; 10(6): 43-55.
[10] Ji J T, Li M Y, Jin X, Pang J, Lv H Z. Experiment on mechanical properties of pepper seedlings based on high-speed and low-loss planting. International Agricultural Engineering Journal, 2017; 26(4): 175-183.

[11] Jin X, Chen K K, Ji J T, Pang J, Du X W, Ma H. Intelligent vibration detection and control system of agricultural machinery engine. Measurement, 2019; 145: 503-510.

[12] Guo J Y. Applicability of 2ZYM-2 type cup-type vegetable transplanter. Journal of Agricultural Mechanization Research, 2018; 40(12): 193-198. (in Chinese)

[13] Ji J T, Sun J W, Jin X, Li M Y, Du X W. Development of a PVDF sensor for potted seedling clamping force of vegetable transplanting. Int J Agric \& Biol Eng, 2019; 12(5): 111-117.

[14] Xiang W, Wu M L, Guan C Y, Xu Y J. Design and experiment of transplanting planting hole forming machine for crawler rapeseed seedlings. Transactions of the CSAE, 2015; 31(15): 12-18. (in Chinese)

[15] Jin X, Yuan Y W, Ji J T, Zhao K X, Li M Y, Chen K K. Design and implementation of anti-leakage planting system for transplanting machine based on fuzzy information. Computers and Electronics in Agriculture. (in press). doi: https://doi.org/10.1016/j.compag.2019.105204

[16] Liu J D, Cao W B, Tian D Y, Ouyang Y N, Zhao H Z. Parameter optimization experiment of automatic transplanter actuator based on mechanical properties of nursery. Transactions of the CSAE, 2016; 32(16): 32-39. (in Chinese)

[17] Han X, Chen H T. Design and optimization experiment of separation mechanism of tomato chain paper seedling transplanter. Transactions of the CSAM, 2018; 49(5): 161-168. (in Chinese)

[18] Xiang W, Wu M L, Xu Y J. Research status and development trend of seedling transplanting machinery. Journal of Agricultural Mechanization Research, 2015; 37(8): 6-9, 19. (in Chinese)

[19] Wang Y W, He Z L, Wang J, Wu C Y, Yu G H, Tang H Y. Experiment on planting performance of automatic transplanting machine for dryland vegetable seedlings. Transactions of the CSAE, 2018; 34(3): 19-25. (in Chinese)

[20] Ni Y L, Jin C Q, Liu J. Design and Experiment of Automatic Seeding System for Automatic Transplanting Machine. Transactions of the CSAE 2015; 31(23): 10-19. (in Chinese)

[21] Jia R C, He Z F, Zhu W C, Liu F M, Li X J, Ye Y Y, et al. Research progress of tobacco transplanter transplantation mechanism. Modern Agricultural Equipment, 2015; 6: 33-39. (in Chinese)

[22] Li H, Cao W B, Li S F, Liu J D, Chen B B, Ma X X. Development of 2ZXM-2 automatic vegetable plug seedling transplanting machine. Transactions of the CSAE, 2017; 33(15): 23-33. (in Chinese)

[23] Ji J T, Yang L H, Jin X, Gao S, Pang J, Wang J L. Design and parameter optimization of planetary gear-train slip type pot seedling planting mechanism. Transactions of the CSAE, 2018; 34(18): 83-92. (in Chinese)

[24] Xu G W, Liu H X, Jian S C, Shi S, He T F. Design and test of transplanting mechanism on Saliva miltorrhiza based on five-bar mechanism. Transactions of the CSAM, 2018; 49(9): 55-65. (in Chinese)

[25] Han C J, Xu Y, Zhang J, You J, Guo H. Design and experiment of semi-automatic compression matrix watermelon seedling transplanting machine. Transactions of the CSAE, 2018; 34(13): 54-61. (in Chinese)

[26] Chen J N, Wang B H, Zhang X, Ren G Y, Zhao X. Kinematics model and parameter analysis of seedling mechanism of multi-rod zero speed seedling transplanting machine. Transactions of the CSAE, 2011; 27(9): 7-12. (in Chinese) 